\title{
Management of Truck Loading Weight: A Critical Review of the Literature and Recommended Remedies
}

\author{
Mozhgan Aliakbari, Sara Moridpoure \\ RMIT University, Melbourne, Australia
}

\begin{abstract}
Traffic accidents involving heavy trucks have social and economic effects on society. However, little research has focused on the influence of heavy truck specifications such as weight. Apportioning the maximum permissible gross weight of trucks allows trucking companies/owners to consolidate loads, and therefore reduce the vehicle-kilometres required to collect and distribute a given amount of goods/material. While drivers/managers are responsible for ensuring that trucks are loaded appropriately and in compliance with regulations, some may take chances and overload vehicles. This increases the need for formal and documented inspections, in order to reduce traffic hazards on public roads due to overweight loading. According to a New South Wales Centre for Road Safety report in 2014, crashes involving heavy trucks often result in serious road trauma outcomes. When a heavy truck is involved in a crash, the vehicle mass raises the crash forces involved and hence increases the severity of the crash. Therefore, interventions should be established to mitigate or prevent these crashes from occurring. Currently, weight checks are required for trucks and truck drivers must drive to a weighbridge for a weight check. Since this is a random process, truck drivers may take the risk of driving an over-loaded truck on some occasions. This paper reviews existing studies concerning safe system interventions in relation to truck gross weight management and a framework is presented to effectively manage truck loading weight. The result may be a reduction of injuries and fatalities involving heavy trucks.
\end{abstract}

\section{Introduction}

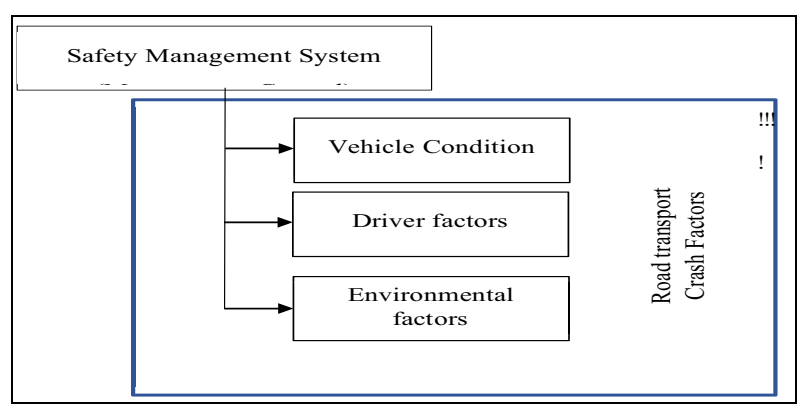

Figure 1. Inter relationship of truck crash factors

Traffic accidents are common on urban highways and rural roads in Australia, resulting in economic and social effects. The main factors responsible for traffic accidents fall into into three classes: driver performance, vehicle and equipment factors, and road and climatic conditions [1]. Fig. 1 illustrates the complex interrelationship between these factors. Vehicle and equipment factors refer to truck specifications such as weight, size and mechanical and operational failure. This is important due to the impact of truck crashes on accident costs. For instance, according to an analysis by the Bureau of
Infrastructure, Transport and Regional Economic (BITRE) in 2006, human expenses (production losses) accounted for $32 \%$ of the standard cost of highway collisions [2]. Vehicle repair followed this cost at $24 \%$, human costs (non-pecuniary) 10\%, human costs (medical and others) $5 \%$ and insurance administration at $8 \%$ of the total average cost of $\mathrm{A} \$ 3,180,598$, including $\mathrm{A} \$ 326,869$ for truck fatalities and serious injuries [3].

\section{Influence of truck gross weight loading on the severity of road crashes}

The number of trucks on Australian roads has increased greatly to $3.3 \%$ of total vehicles. This increase poses safety challenges for road users in terms of possible accidents, and trucks are involved in almost $15 \%$ of all fatal accidents in Australia [1]. However, the implementation of the Safety Management System reduced the number of fatal crashes involving trucks from 276 in 2005 to 220 in 2014.

According to the aggregate fatal crash data in Australia compiled by BITRE (2014) [4], trucks in Australia are classified as either rigid or articulated (see Fig. 2). 


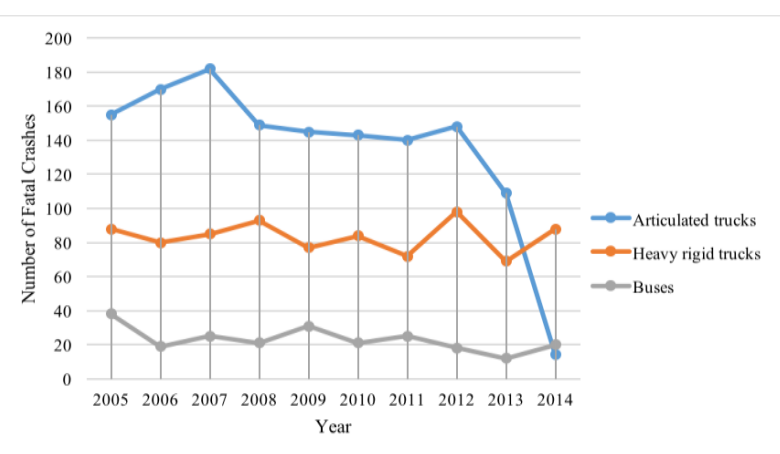

Figure 2. Fatal crashes by type of truck.

The BITRE report (2014) [4] further shows that two thirds of the articulated trucks and one third of the rigid trucks were involved in fatal accidents, as presented in Table 1.

TABLE 1. Number of Fatal Crashes by Type of Truck Involved, Australia 2005-20104

\begin{tabular}{|c|c|c|c|}
\hline \multirow{2}{*}{ Year } & \multicolumn{3}{|c|}{ Type of trucks } \\
\cline { 2 - 4 } & Articulated trucks & $\begin{array}{c}\text { Heavy rigide } \\
\text { trucks }\end{array}$ & Buses \\
\hline 2005 & 155 & 88 & 38 \\
\hline 2006 & 170 & 80 & 19 \\
\hline 2007 & 182 & 85 & 25 \\
\hline 2008 & 149 & 93 & 21 \\
\hline 2009 & 145 & 77 & 31 \\
\hline 2010 & 143 & 84 & 21 \\
\hline 2011 & 140 & 72 & 25 \\
\hline 2012 & 148 & 98 & 18 \\
\hline 2013 & 109 & 69 & 12 \\
\hline 2014 & 14 & 88 & 20 \\
\hline
\end{tabular}

Several factors have been cited for this phenomenon, with truck gross weight being the most significant [5]. The loading weight plays a significant role in determining the severity of traffic accidents involving trucks. Collisions involving heavy vehicles frequently lead to serious disturbances to roads, because when a heavy articulated vehicle is in an accident, the mass of the vehicle increases the accidental forces and consequently amplifies the seriousness of the collision [5]. The present crash rate in Australia is 2.5 victims per 100 million truck kilometers traveled [6]. The severity of accidents involving heavy trucks is high because of the high impact magnitude as a result of trucks' gross weight (refer to Fig. $3)$.

The effect of the gross load weight of trucks involved in accidents is more pronounced for long trucks with several combinations, such as tractor semi-trailers plus trailers or tractor semi-trailers alone. These truck combinations have double the crash rate of rigid trucks. For instance, there is a high fatal crash rate of $8.6 \%$ per hundred million vehicle miles for truck combinations compared to rigid trucks [7]. This shows that truck gross loading weight affects the severity of accidents.

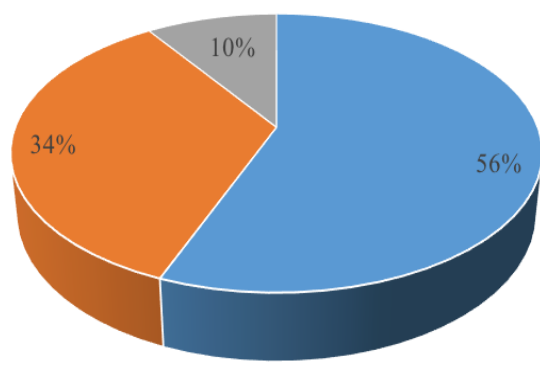

-Articulated trucks " Heavy rigid trucks "Buses

Figure 3. Percentage of fatal crashes by type of truck involved, Australia 2005-20104 [4].

Studies of the influence of truck loading weight on the severity of accidents have reported similar trends. For instance, truck load combinations involving unfilled and near-empty trucks registered relatively elevated collision participation rates with a factor of two compared to loaded trucks [7]. It is important to note that the impact of truck gross load on accidents is dependent on the exposure of unfilled trucks and their participation in these accidents [8].

Other studies elsewhere have reported low accident involvement rates for heavily-loaded trucks, with empty or partially-empty trucks reporting high accident involvement rates [7]. These findings are supported by engineering assumptions that empty trucks are dynamically less stable compared to loaded trucks and have an inherent inability to generate braking force compared to high weight trucks [6]. In addition, unloaded trucks are characterized as having longer braking distances in comparison with loaded trucks. High crash rates have been reported for empty combinations of single-unit trucks due to premature wheel lock-up and associated stability issues, because truck brakes characteristically work more efficiently under loaded conditions [8]). These findings show the relationship of increased gross truck weight to braking performance. It has been shown that truck gross weight and braking performance are inversely proportional, implying that for these trucks to attain acceptable levels of brake performance, they should have certain weight loadings, thus minimizing the severity of truck accidents [9].

In addition, the number of truck victims in Australia showed a wide variation from 2005-2010. In 2005, fatalities were 235 , escalating to 272 in 2008 and reducing to 216 for the duration of the global financial crisis of 2009. The number increased further to 237 in 2010. Based on the truck type, a similar trend for crashes was observed with two-thirds articulated trucks and onethird rigid trucks accounting for these fatalities. However, fatal deaths and crashes involving trucks have remained relatively constant since 1991, with the lowest number of cases reported in 2003 [10]. Over the same period, the number of trucks on Australian roads increased by $18 \%$ 
with a $37 \%$ increase in the kilometres traveled and a $70 \%$ increase in tonne-kilometres [4], as summarized in Figure 2 . This phenomenon can be attributed to improvements in truck safety since 2002 (see Fig. 4)

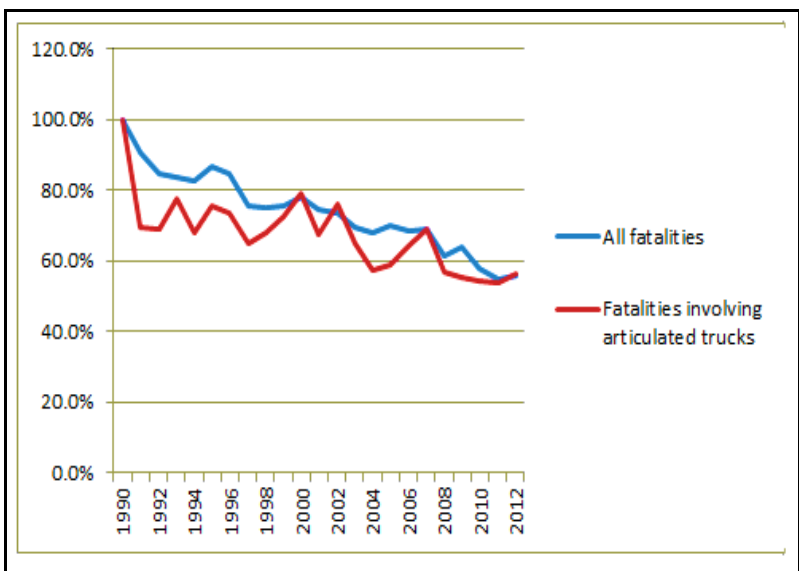

Figure 4. Total road deaths compared to those involving articulated trucks, 1986-2012 [4].

\section{Existing safety system interventions with regard to truck gross weight management}

\subsection{The use of truck tracking technology}

Technology has been adopted since the 1980s to manage the risk of overloaded trucks and to collect heavy vehicle data on highways 11]. Weigh-In Motion (WIM) sensors on highways (such as piezoelectric, bending plate, load cell, and quartz sensors) are employed to measure the weight of axle(s), and communication systems are used for data transmission to a database. The latest wave of electronic technology is telematics systems to bring more quality, effectiveness and improved ability to detect overloaded vehicles [12].

The existence of new technologies reduces the gap between the available safe system measures and measures taken to detect overloaded trucks and reduce the risk to traffic safety. However, the use of WIM is sophisticated and expensive because of Australia's vast distances, dispersed roads and highways. Furthermore, the use of telematics is disputed within the trucking industry and between the industry and the government in relation to whether it should have a regulatory function in order to make the data collected available to regulators to check industry compliance with the rules [11] [12] [13].

\subsection{Government safety system interventions}

To ensure road safety, the Australian Government has regulated the gross weight loading of trucks plying urban highways and rural roads. The maximum allowable truck sizes and weight limits for these trucks are specified as follows: 80,000 pounds gross weight and axle weight of up to 20,000 and 34,000 pounds for single and double axles and size limits of 102 inches (width) by 48 feet (length) [14]. To enforce the law on maximum permissible truck loads, the government through the
Australian Transport Council (comprising of ministers in charge of transport from the Australian federal government, states and territories and observers from local governments) developed the National Heavy Vehicle Safety Action Plan 2003-2005 [14] and the National Heavy Vehicles Safety Strategy 2003-2010 [9]. The strategy complements the National Road Safety Strategy 2001-2010 by focusing on critical impacts in an attempt to lessen deaths and injuries relating to heavy trucks. The objective of the heavy vehicle stratagy is to facilitate the implementation of a $40 \%$ mortality reduction in the national policy target, thereby reducing the Australian heavy vehicle crash rate to low global rates. To achieve this, the strategy highlights eight objectives: extra effective rate management, reduced driver injury, safer heavy vehicles, augmented seat belt employment by drivers, safe roads, effective enforcement, enhanced driver and business administration and improved investigation and education. Other safety system interventions geared towards minimizing the severity of heavy truck crashes include the adoption of modern stateof-the-art technologies such as adaptive cruise control, installation of collision warning and avoidance systems and speed limiters to help truck drivers avoid risky situations that could result in truck crashes and deaths. These complement the government regulation of the maximum and minimum gross weight of these trucks. It has been observed that regulations on the highest and lowest gross weight alone without supportive measures will not assist in reducing the number and severity of accidents arising from heavy trucks on Australian roads [15]. This combined effort will help in attaining internationally recommended and acceptable crash rates.

To effectively address the increasing number of fatal accidents in Australia, other factors affecting the safety of heavy trucks should be addressed. These include, but are not limited to, lane-departure and curve speed warnings, electronic stability control and braking, and trucks' mechanical condition in terms of brake efficiency. The government road safety strategy has addressed these factors adequately through improved maintenance of road conditions, improved compliance with existing rules and extending and refining enforcement programs. These provide additional safety for trucks [16]. To ensure the effectiveness of the road safety strategy, educational training and awareness programs play an important role, by training truck drivers on the adverse effects of not following traffic rules strictly. Drivers are also reminded periodically of the need to load their trucks within the recommended gross weight range to reduce fatal truck crashes in Australia [17].

The government of Australia through the relevant bodies has instituted rigorous roadside inspection programs with the objective of ensuring that the trucks plying both urban and rural roads adhere to various requirements such as the minimum and maximum gross weights. Secondly, these inspection programs serve to ensure that heavy trucks carry the necessary safety devices such as speed limiters and adaptive cruise control [17].

Truck design is an important safety system intervention in addressing truck crashes and deaths in 
Australia due to its impact on the severity of truck collisions with other road users such as light vehicles on urban highways and rural roads [16]. Truck design affects truck stability in terms of weight distribution. In the case of an error in truck design, there will be increased instances of truck accidents [18] [27].

\section{Possible remedies and framework}

The Australian government through its agency the Australian Transport Council should increase its efforts in dealing with crashes and deaths involving trucks with excess loads. The current accident prevention measures in Australia focus on three issues: drivers, roads, and vehicles. For instance, in one study of major fatal truck deaths and crashes, driver fatigue accounted for $10 \%$ of crashes and speeding was responsible for 32\% [18] [19]. In relation to vehicle factors, current control measures emphasize truck design, management of speed of trucks and the introduction of engineering measures such as black spot programs in addition to large-scale implementation of cost- effective measures in the heavy truck sector with the objective of improving road safety. These measures aim for the improvement of the road network all over Australia.

However, these measures have proven inadequate, since they have failed to address accidents involving heavy trucks. The main reason for the inadequacies in the current system is overlooking the impact of gross weight on crashes and deaths involving trucks [20]. This has led to the establishment of weighbridges on major highways to check whether trucks adhere to the permissible gross weights advised by the law. However, some drivers take the risk of either driving overloaded vehicles or avoiding these weight checks since in the current system, weight checking is a random exercise, allowing some overloaded trucks to go unchecked [20].

In the United States, there have been proposals on truck size and weight liberalization to eliminate the heavy five-axle tractor semi-trailers to reduce the weight of trucks in an attempt to minimize fatalities and accidents involving these trucks. This culminated in the removal of the Federal bridge formula's 80,000 pound restriction on truck loads. The removal of this cap enabled weight reduction of trucks, thus reducing truck gross loading weight and the associated accident severity [21]. In Brazil, the authorities have established minimum truck size-andweight restrictions through compulsory weight checks with the objective of minimizing truck accidents. However, some truck drivers and owners/companies still overload their trucks, as reports show that $20 \%$ of the trucks passing through weigh stations are overloaded [20]. The existence of gaps in current laws have made them ineffective, as truck accidents have been on the rise with $60 \%$ of the trucks involved in accidents being overloaded [23]. There is a need for the authorities to formulate complementary regulations to complement these laws, thus managing truck gross weight loading and the severity of truck accidents [24].

The study of existing control measures as explained above suggests that the risk of catching an overloaded vehicle is relatively low, at least when the route is outside the areas where weigh-in-motion systems are employed or where the presence of enforcement personnel is expected [24] [25]. Therefore, for planning purposes, comprehensive traffic and weight data are essential to advance the system and collect reliable forecasts of road users both on highways and in rural areas [27]. A combined traffic data collection and enforcement regime is possible using the framework shown in Fig. 5.

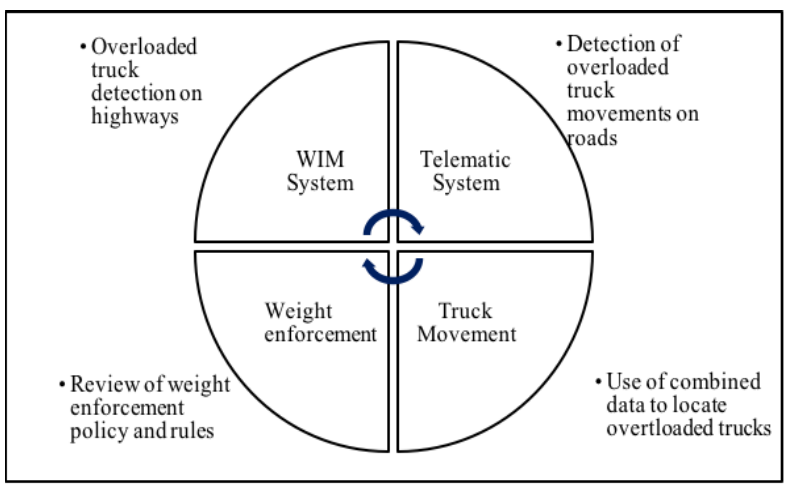

Figure 5. Overload truck management framework enforcement effectiveness.

The combination of the information collected by the traffic data collection system will lead to continuous reviewing of road traffic policies and rules on weight enforcement and make a significant contribution to road transport safety. However, the weight enforcement and traffic data collection activities may not be reduced. In fact, the overall coverage and effectiveness may significantly increase [28].

\section{Conclusion}

To improve the effectiveness of weight checks, the Australian government should adopt a compulsory as opposed to random formal and documented inspection process for all trucks. This will involve the certification and stamping of official documents as proof that the trucks have undergone weight checks, with the particulars of the inspection stations and authority personnel who checked these trucks, and endorsements as to whether or not the truck gross weight is within the recommended values. This should be followed by confirmation of whether or not the trucks went through weight checks on different locations along the road by confirming and checking details and particulars obtained from weigh stations as contained in relevant official documents. The Road Safety Authority should also enact laws to deal with truck drivers and owners/companies found driving overloaded trucks. This will help in managing truck gross weight loading by eliminating overloading of these trucks, hence minimizing the severity of accidents involving trucks.

\section{References}

1. Trucking Association, 2011-2013 Strategic Plan. Forrest Canberra, Australia 2603. (2010) 
2. Deighton-Smith, R., Review of the Road Safety Remuneration System Final Report, Australia , pp 10-101, (2016)

3. BITRE (Bureau of Infrastructure, Transport and Regional Economics), Road crash costs in Australia 2006, Report 118. Canberra, Australia, (2009)

4. BITRE (Bureau of Infrastructure, Transport and Regional Economics), Road Deaths Australia 2011 statistical summary, Canberra , Australia, (2014)

5. New South Wales Centre for Road Safety, Road traffic crashes in New South Wales: Statistical Statement for the year ended 31 December 2013, Government of New South Wealth, Australia, (2014)

6. Driscoll, O. P. , Major Accident Investigation Report 2013.National Truck Accident Research Centre. Brisbane, Australia, (2013)

7. af Wåhlberg, Anders E. "Meta-analysis of the difference in accident risk between long and short truck configurations." Journal of Risk Research 11.3, pp 315-333, (2008)

8. National Heavy Vehicles Safety Strategy. (2001), Retrieved January 11, 2013, from National Heavy Vehicle Safety Strategy 2003-2010, Australian Transport Council, (2001) Available www.ntc.gov.au/DocView.aspx?page=A0220831630 1560020

9. National Heavy Vehicle Safety Action Plan. (2001, September 3). Retrieved May 5, (2010) from Australian Transport Council, Available

www.ntc.gov.au/DocView.aspx?page $=$ A0220850730 0550020, 2010.

10. Wilson, L.J. and T.W. Horner, Data Analysis of Tractor- Trailer Drivers to Assess Driver's Perception of Heavy Duty Truck Ride Quality, Final Report, No.: DOT-HS•805-139 PB-8•0-118144, (2009)

11. O'Brien, Eugene J., et al. "Direct measurement of dynamics in road bridges using a bridge weigh-inmotion system" pp 263-270, (2013)

12. Mikulski J. Introduction of telematics for transport. InELEKTRO, 2012, pp. 336-340. IEEE, (2012)

13. Jarossi, Linda, Anne Matteson, and J. Woodrooffe. "TRucks involved in Fatal Accident Fact Book 2006, University of Michigan Transportation Research Institute." Retrieved September 8 (2008)

14. National Heavy Vehicle Safety Action Plan. (2001, September 3). Retrieved May 5, 2010, from Australian Transport Council,(2010) Available

www.ntc.gov.au/DocView.aspx?page $=$ A0220850730 0550020

15. Raftery, SJ; Grigo, JAL; Woolley, JE. , "Heavy vehicle road safety: A scan of recent literature". Journal of the Australasian College of Road Safety, 22(3), pp 18-24, (2011)
16. Scott-Parker, B., Goode, N., \& Salmon, P., The driver, the road, the rules... and the rest? A systemsbased approach to young driver road safety. Accident Analysis \& Prevention, 74, pp 297-305, (2015)

17. Newton, J., Howard, E., \& Wishart, D. , A Guide to Applying Road Safety within a Workplace: A Bilateral Approach to Organisational Road Safety in Australia and New Zealand, (2013)

18. de Pont, J., 2014, October. Prescriptive limits or performance based standards?. In HVTT13: International Symposium on Heavy Vehicle Transport Technology, 13th, San Luis, Argentina, (2014)

19. Edgar, J., Regulating heavy vehicle safety in New Zealand using performance standards. In Fourth International Symposium on Heavy Vehicle Size and Weight. Ann Arbor, MI. International Symposium on Heavy Vehicle Weights and Dimensions. Michigan, pp. 115-119, (1995)

20. Tziotis, M., Recent Australian Road Research Board research on heavy vehicle safety, Journal of the Australasian College of Road Safety, 22,(3), pp 22(3), (2011)

21. Woodrooffe, J., \& Blower, D. , Survey of the status of truck safety: Brazil, China, Australia, and the United States, (2012)

22. Ribeiro, Sandra Furlan, and R. R. José. "Road accidents in Brazil." IATSS research 29.2 , pp 68-70, (2005)

23. Blower, D., \& Woodrooffe, J., Survey of the status of truck safety: Brazil, China, Australia, and The United States, University of Michigan Transportation Research Institute, (2012)

24. Smith, R.D, Review of the road Safety Remuneration System, Jaguar Consulting Pty Ltd, Australia, pp10$65,(2014)$

25. Sharwood, L.N.; Elkington, "Large Truck Accident Causation, "National Highway Traffic Safety Administration Technical Report No. DOT HS-806300, (2012)

26. Franke, R., \& Shinstine, D. S. , Effects of Truck Traffic on Crash Injury Severity on Rural Highways in Wyoming using Bayesian Binary Logit Models 2. Transportation Research, pp 42-43, (2014)

27. BITRE(Bureau of Infrastructure, Transport and Regional Economics), Truck productivity: sources, trends and future prospects, Report 123, Canberra, Australia Canberra, (2011)

28. Castillo-Manzano, J. I., Castro-Nuño, M., \& Fageda, X., Exploring the relationship between truck load capacity and traffic accidents in the European Union. Transportation research part E: logistics and transportation review, 88, pp 94-109, (2016)

29. Steadman, L. A., \& Bryan, R. J., Cost of Road Accidents in Australia. Canberra, Australia, (2013) 